\title{
O CONSENTIMENTO INFORMADO EM PORTUGAL: BREVES NOTAS
}

CONSENT INFORMED IN PORTUGAL: NOTES

André Gonçalo Dias Pereira ${ }^{1}$

ISSUE DOI: $10.21207 / 1983.4225 .599$

\section{RESUMO}

Ao longo do Século XX, a ética médica abandonou progressivamente o paternalismo hipocrático, para respeitar a autonomia do paciente. Ao nível do direito, afirmou-se o dever de o profissional de saúde prestar informações com vista a permitir a autodeterminação da pessoa, que tem o direito a consentir ou a recusar a intervenção propos-ta. Estes direitos foram consagrados a nível do direito internacional dos direitos humanos, do direito penal, direito civil e em legislação específica da área da saúde,

\footnotetext{
1 Professor da Faculdade de Direito da Universidade de Coimbra; Diretor do Centro de Direito Biomédico da Universidade de Coimbra; Membro do Conselho Nacional de Ética para as Ciências da Vida; Governor da Associação Mundial de Direito Médico; Fundador e Vice-Presidente da ALDIS - Associação Lusófona de Direito da Saúde; Autor das obras: O Consentimento Informado na Relação Médico-Paciente. Estudo de Direito Civil, Coimbra, Coimbra Editora, 2004 e Direitos dos Pacientes e Responsabilidade Médica, Coimbra, Coimbra Editora, 2015. ORCID iD 0000-0001-9871-5298
} 
vindo, finalmente, a ser acolhido pela jurisprudência, inclusive pelo Supremo Truibunal de Justiça português em 2015.

Palavras-chave: Direito da medicina. Ética médica. Consentimento informado. Direito português. Convenção sobre os Direitos do Homem e a Biomedicina.

\section{ABSTRACT}

Throughout the 20th century, medical ethics progressively abandoned Hippocratic paternalism, in order to respect the autonomy of the patient. At the level of the law, it was stated that the health professional must provide information in order to allow the self-determination of the person, who has the right to consent or to refuse the intervention proposed. These rights have been enshrined in international human rights law, criminal law, civil law and specific legislation in the area of health, and it has finally been accepted by jurisprudence, including by the Portuguese Supreme Truibunal Court in 2015.

Keywords: Law of medicine. Medical ethics. Informed consent. Portuguese law. Convention on Human Rights and Biomedicine.

\section{ASPETOS HISTÓRICOS}

$\mathrm{Na}$ antiguidade grega, Hipócrates afirmava: “As coisas sagradas não se revelam senão aos homens sagrados, é proibido comunicá-las aos profanos, porque não foram iniciados nos mistérios da ciência."2 Nos dias de hoje, o panorama legal do ato médico é distinto. $\mathrm{O}$ respeito pela autonomia do paciente e a exigência do consentimento livre e esclarecido estão claramente estabelecidos na ética e no direito médico, verificandose um abandono do paternalismo clínico.

Ao longo do processo de evolução da doutrina do consentimento informado, algumas decisões judiciais e documentos internacionais

\footnotetext{
2 Raymond VILLEY, Histoire du Secret Médical, Paris, Seghers, 1986, p.15, apud Guilherme de OLIVEIRA, "O fim da "arte silenciosa", Temas de Direito da Medicina, 2. ${ }^{a}$ Edição, Coimbra, Coimbra Editora, 2005, p. 106.
} 
constituíram-se como marcos históricos devido à sua relevância e caráter inovador.

Estando esta obra recheada com os mais importantes casos norte-americanos, serão apresentados aqui alguns dos casos históricos de países europeus:

- Em 1767, o caso Slater versus Baker \& Stapleton consagrou a primeira sentença inglesa no âmbito do direito ao consentimento, ao condenar dois médicos que atuaram sem o prévio consentimento do paciente;

- Quase um século depois, em 1859, o Tribunal Correcional de Lyon, em França, declarou que as obrigações do médico perante a ciência não podiam ir além do respeito devido ao doente, em especial por estarem, em causa, experiências sendo realizadas em menores, incapazes de darem o seu consentimento livre e esclarecido;

- O Tribunal do Império (alemão) (Reichsgericht) decidiu o caso do Médico chefe de serviço acusado de ofensas corporais. O médico amputara o pé de uma criança de 7 anos, devido a um abcesso tuberculoso do osso do tarso. O pai da criança era um defensor da medicina naturalista e, por princípio, contrário à cirurgia, e tinha-se oposto à operação. $\mathrm{O}$ tribunal considerou a intervenção médica como ofensas corporais, que apenas poderiam ser justificadas através do consentimento do pai (titular do poder paternal);

- A 28 de Janeiro de 1942, a Cour de Cassation consagrou o dever de obter o consentimento do paciente antes de qualquer intervenção.

\section{CONSELHO DA EUROPA}

Com relação ao Conselho da Europa, deve-se tomar em consideração, desde logo, o seu documento matriz: a Convenção Europeia dos Direitos do Homem (Convenção para a Proteção dos Direitos do Homem e das Liberdades Fundamentais). ${ }^{3}$

${ }^{3}$ Aprovada para ratificação pela Lei n. ${ }^{\circ}$ 65/78, de 13 de Outubro, publicada no Diário da República, I Série, n. ${ }^{\circ}$ 236/78 (rectificada por Declaração da Assem- 
Segundo a doutrina internacional e a jurisprudência do Tribunal Europeu dos Direitos do Homem, o artigo $8^{\circ}$ da CEDH protege o paciente de intervenções arbitrárias. Esta norma assegura o respeito do direito à vida privada, mas tem sido erigida como porta-estandarte do direito ao consentimento informado no âmbito da CEDH. A jurisprudência dos órgãos da Convenção indica claramente que uma intervenção biomédica praticada sem o consentimento do indivíduo constitui uma ingerência na sua vida privada. ${ }^{4}$

A atividade do Conselho da Europa é ainda muito relevante quanto aos outros documentos (Resoluções, Declarações) que embora não sejam vinculativos assumem um papel valioso.

Finalmente em 1996, foi aprovada, em Oviedo, Astúrias, Espanha, a Convenção sobre os Direitos do Homem e a Biomedicina, ${ }^{5}$ cujo artigo $5^{\circ}$ proclama o direito ao consentimento informado nos seguintes termos:

1. Qualquer intervenção no domínio da saúde apenas pode ser efectuada depois da pessoa em causa dar o seu consentimento de forma livre e esclarecida.

2. A esta pessoa deverá ser dada previamente uma informação adequada quanto ao objectivo e à natureza da intervenção, bem como às suas consequências e os seus riscos.

3. A pessoa em causa poderá, a qualquer momento, revogar livremente o seu consentimento.

\section{UNIÃO EUROPEIA}

bleia da República publicada no Diário da República, I Série, n. ${ }^{\circ}$ 286/78, de 14 de Dezembro).

${ }^{4}$ Casos X. vs. Áustria (exame de sangue em ação de filiação) e Associação X. vs. Reino Unido (vacinação que resultou em morte de crianças).

${ }^{5}$ Convenção para a Proteção dos Direitos do Homem e da Dignidade do Ser Humano relativamente às Aplicações da Biologia e da Medicina: Convenção sobre os Direitos do Homem e a Biomedicina. Adoptada e aberta à assinatura em Oviedo, a 4 de Abril de 1997. Aprovada, para ratificação, pela Resolução da Assembleia da República n. ${ }^{\circ} 1 / 2001$, de 3 de Janeiro. 
No âmbito da União Europeia destaca-se a consagração expressa do direito ao consentimento informado na Carta dos Direitos Fundamentais da União Europeia: ${ }^{6}$

Artigo 3. ${ }^{\circ}$ - Direito à integridade do ser humano

1. Todas as pessoas têm direito ao respeito pela sua integridade física e mental.

2. No domínio da medicina e da biologia, devem ser respeitados, designadamente:

- o consentimento livre e esclarecido da pessoa, nos termos da lei,

- a proibição das práticas eugénicas, nomeadamente das que têm por finalidade a seleção das pessoas,

- a proibição de transformar o corpo humano ou as suas partes, enquanto tais, numa fonte de lucro,

- a proibição da clonagem reprodutiva dos seres humanos.

Já anteriormente, o Parlamento Europeu havia aprovado a Carta Europeia dos Direitos dos Pacientes, ${ }^{7}$ na qual se enumera um conjunto de direitos com vistas a proteger a pessoa doente. A Carta Europeia dos Direitos do Paciente, redigida em 2002, pela Active Citizenship Network, foi bem acolhida pelo Comitê Econômico e Social Europeu no Parecer do Comitê Econômico e Social Europeu sobre "Os direitos do paciente" (2008/C 10/18), de Janeiro de 2008. ${ }^{8}$

\section{DIREITO PORTUGUÊS}

O ordenamento jurídico português confere uma ampla tutela ao direito à autodeterminação da pessoa humana, quer no plano do direito constitucional, quer no plano do direito penal, civil e da legislação própria do direito da saúde. Por outro lado, a Convenção Europeia dos Direitos

\footnotetext{
${ }^{6}$ O Tratado de Lisboa incorpora a Carta dos Direitos Fundamentais da União Europeia, pelo que estes direitos gozam de força normativa plena.

${ }^{7}$ Carta Europeia dos Direitos do Paciente, Resolução de 19 de Janeiro de 1984, JOCE C 46, de 20 de Fevereiro de 1984, p. 104.

${ }^{8}$ Jornal Oficial da União Europeia, 15.1.2008, C 10/67 ss.
} 
do Homem e da Biomedicina (do Conselho da Europa) foi ratificada por Portugal, sendo um dos seus princípios fundamentais o consentimento informado.

O Código Penal Português pune a intervenção médica realizada sem o consentimento do paciente com o tipo de intervenções ou tratamentos médico-cirúrgicos arbitrários (artigo $156^{\circ}$ ) e prescreve o dever de esclarecimento (artigo $157^{\circ}$ ) como condição de eficácia do consentimento. Este regime das intervenções médico-cirúrgicas de índole terapêutica garante ao profissional de saúde um regime mais favorável no plano criminal, já que estas técnicas se encontram no âmbito da atipicidade relativamente às ofensas à integridade física. ${ }^{9}$

Quando a intervenção médica não for praticada por um médico ou outra pessoa legalmente habilitada, ou não tenha finalidade terapêutica ou ainda se não seguir as leges artis da medicina acadêmica, só será lícita se previamente justificada com o consentimento do lesado (artigos $38^{\circ}$ e $149^{\circ} \mathrm{CP}$ ). Estas normas são de uma importância crucial na regulação do direito ao consentimento informado no nosso ordenamento jurídico.

A Direção-Geral da Saúde é um serviço central do Ministério da Saúde, integrado na administração direta do Estado, dotado de autonomia administrativa, dita o Decreto Regulamentar n. ${ }^{\circ}$ 14/2012. Afirma o art. ${ }^{\circ} 2 .^{\circ}$ n. ${ }^{\circ} 2$ desse diploma que "A DGS prossegue as seguintes atribuições: a) Emitir normas e orientações, quer clínicas quer organizacionais, desenvolver e promover a execução de programas em matéria de saúde pública e para melhoria da prestação de cuidados em áreas relevantes da saúde, nomeadamente nos cuidados de saúde primários, hospitalares, continuados e paliativos." Com base nesta lei, foi publicada no dia 14 do mês de outubro de 2013, no site da Direção Geral de Saúde, a Norma 15/2013 relativa ao consentimento informado, livre e dado por escrito.

Trata-se de uma norma de caráter organizacional que revogou a Circular Informativa n. ${ }^{\circ}$ 15/DSPCS de 23-03-1998. A Norma afirma ter como destinatários as Administrações Regionais de Saúde, dirigentes de unidades de saúde e profissionais de saúde do sistema de saúde.

\footnotetext{
${ }^{9}$ Para mais desenvolvimentos, ANDRADE, Manuel da COSTA, "Comentário ao artigo 150.", in DIAS, Jorge de FIGUEIREDO (Org.), Comentário Conimbricense ao Código Penal, Coimbra, Coimbra Editora, 2. ${ }^{a}$ Edição, 2012.
} 
Esta Norma 15/2013 tem influenciado no sentido de uma maior implementação da prática de obter o consentimento do doente, por escrito, no âmbito das intervenções médicas, em especial médicocirúrgicas. Necessário seria que no cumprimento regular desta Norma, o consentimento dos doentes seja mais informado e mais livre e não se transforme num mero formalismo burocrático.

Comecemos pelos dados que nos parecem mais positivos:

- o fato de haver espaço disponível no formulário para que o médico insira a informação adequada ao procedimento concreto e que seja útil ao processo de esclarecimento que está a realizar (1-a);

- a obrigatória inserção do consentimento informado no processo clínico (1-b e 6);

- o fato de o doente poder ficar com uma cópia do formulário do CI (4-a);

- o fato de o doente poder identificar e guardar a informação acerca da instituição e do profissional que participou no processo de CI (4-b e c);

- a exigência da informação acerca dos riscos graves associados ao ato/ procedimento, bem como das alternativas de tratamento (4-f);

- a valorização do procurador de cuidados de saúde (7);

- a valorização da participação do menor que tenha capacidade de discernimento (Anexo: solicita-se a assinatura do menor).

Numa leitura crítica, podem-se apontar algumas limitações a esta Norma 15/2013.

A primeira deriva da sua natureza jurídica. Como visto, trata-se de uma Norma exarada da autoridade do Diretor Geral de Saúde, com o valor normativo limitado, o que determina o seu alcance, pois apenas se procura organizar de forma sintética todo um instituto jurídico que se encontra disperso pelo ordenamento jurídico (Código Civil, Código Penal, Lei n. ${ }^{\circ}$ 15/2014, de 21 de março (direitos e deveres dos utentes do sistema de saúde), Convenção sobre os Direitos do Homem e a Biomedicina, etc.). Mas não basta colocar ordem na dispersão normativa; é necessário tomar algumas decisões de política legislativa que se prendem aos direitos, liberdades e garantias. Assim, alguns dos problemas mais importantes e práticos do consentimento carecem de uma 
intervenção legal: ao nível de Lei ou Decreto-Lei autorizado. Referimonos a questões como:

1. a definição de um critério jurídico firme, por exemplo uma idade, para que os adolescentes tenham capacidade para consentir;

2. a determinação de um caminho para fazer face à situação dos incapazes adultos de fato, ou seja, de todas aquelas pessoas que por senilidade, demência, doença mental ou outros estão incapazes de discernimento para consentir ou recusar intervenções médicas: deveríamos seguir o caminho de um consentimento por substituição a ser dado pelos familiares próximos ou deveremos manter o sistema do consentimento presumido em que os familiares e outras pessoas próximas são chamadas para um processo de decisão partilhada com a equipe médica, tendo sempre em conta a vontade presumível do paciente (art. 340, n. 3 do Código Civil)?

Esta Norma poderá ter o condão de habituar os médicos a discutir com os seus doentes o processo terapêutico, com mais detalhe, com mais esclarecimento e com mais profundidade. Essa tomada de consciência dos riscos inerentes à intervenção, a escolha entre alternativas possíveis vai não só promover a autodeterminação das pessoas doentes e cimentar uma relação mais democrática e transparente, mas vai ainda contribuir para a segurança do tratamento, pois o doente estará mais alerta para eventuais eventos adversos, e finalmente, vai contribuir para a humanização dos cuidados de saúde e conduz necessariamente a uma melhor relação pessoal e profissional entre o médico e o paciente: condição primeira para a adesão à terapêutica e consabidamente, o melhor antídoto para problemas judiciais.

Afirma - com justiça - o Supremo Tribunal de Justiça de 9-102014 (João Bernardo):

[...] a referência num documento assinado por médico e doente a que aquele explicou a este de forma adequada e inteligível entre outras coisas os riscos e complicações duma cirurgia não permite ajuizar da adequação e inteligibilidade e bem assim dos riscos concretamente indicados" pelo que é manifestamente insuficiente. 
O médico deve ativamente cumprir o seu dever de informar oralmente e, seguindo o comando da Norma 15/2013, deve registar por escrito no espaço próprio do formulário obrigatório (4):

“d) Identificar o ato/ intervenção proposto e a sua natureza;

e) Descrever o diagnóstico e a situação clínica e os objetivos que se pretendem alcançar com o ato/ intervenção proposto;

f) Identificar os potenciais benefícios, riscos frequentes e riscos graves associados ao ato/ procedimento e as eventuais alternativas viáveis e cientificamente reconhecidas;

g) Identificar os potenciais riscos decorrentes de uma não intervenção em caso de dissentimento".

Um outro aspeto sempre controverso é o de saber se o médico tem o dever de informar dos riscos graves ainda que raros ou excepcionais. Em sentido negativo pronunciou-se o STJ em 9/10/2014, ao afirmar que não se exige uma "referência à situação médica em detalhe, nem a referência aos riscos de verificação excepcional ou muito rara mesmo que graves ou ligados especificamente àquele tratamento."

Por seu turno, a Norma da DGS, republicada a 14/10/2014, também deixa margem para diferentes interpretações, pois estatui que o médico deve indicar "os riscos frequentes e riscos graves associados ao ato/ procedimento". Donde, pode-se concluir que a chave da solução do problema deverá passar pela destrinça entre intervenções voluntárias (de natureza estética, anticoncepcional ou inovadora) e as intervenções médicas terapêuticas, exigindo-se nas primeiras uma informação mais detalhada ou mesmo exaustiva dos riscos graves. Era nesse sentido que se pronunciava o Projeto de Lei $\mathrm{n}^{\circ} 413 / \mathrm{XI} / 2$. $^{a}$ sobre Direito dos doentes à informação e ao consentimento informado, no n. ${ }^{\circ} 5$ do seu artigo 2. ${ }^{\circ}$. "A informação é tanto mais pormenorizada e extensa quanto menor for o intuito terapêutico da intervenção ou quanto mais graves forem os seus riscos." 
O Supremo Tribunal de Justiça, no Acórdão de 2 de junho de 2015 (Relatora: Clara Sottomayor), afirmou claramente a responsabilidade civil por violação do consentimento informado, tratando-se de um caso que vem orientando a jurisprudência, tanto na jurisdição comum (que julga os litígios emergentes em hospitais), como na jurisdição administrativa (que julga os litígios ocorridos em hospitais públicos), no sentido do respeito dos direitos dos pacientes, em especial do direito ao consentimento informado.

Segundo se conhece é esta a primeira vez que o Supremo Tribunal condena um médico por violação do dever de obter o consentimento (informado). Antes de 2015, o direito ao consentimento informado havia sido afirmado pelo STJ em, pelo menos, duas ocasiões; todavia, nesses dois casos a decisão foi de absolvição do Réu: Acórdão do Supremo Tribunal de Justiça de 18 de março de 2010 (Relator: Pires da Rosa); e Acórdão do Supremo Tribunal de Justiça de 9 de outubro de 2014 (Relator: João Bernardo).

A partir desta decisão, de 2/6/2015, torna-se claro que a Jurisprudência reconhece todos os efeitos civis da violação do consentimento informado. Em suma: serão assim ressarcíveis, não só os danos não patrimoniais causados pela violação do seu direito à autodeterminação e à liberdade, mas também por violação da sua integridade física (e, eventualmente, da vida), bem como os danos patrimoniais derivados do agravamento do estado de saúde. Assim sendo, o montante das indemnizações resultantes de um processo de responsabilidade por violação do consentimento informado pode ser tão elevado como os casos de negligência médica.

No mesmo sentido, decidiu o Acórdão do Supremo Tribunal de Justiça de 16-06-2015 (Relator: Mário Mendes), acrescentando ainda que "a verificar-se uma situação de intervenção médico-cirúrgica não autorizada ou não validamente informada (consequentemente ilícita) estaremos desde logo, tout court e independentemente de outros danos ressarcíveis, perante um dano não patrimonial autônomo indenizável." E acrescenta este aresto que "em princípio e independentemente de se fazer especial apelo ao princípio da colaboração processual em matéria de prova, compete ao médico provar que prestou as informações devidas."

Das várias figuras analisadas no importante Acórdão de junho de 2015, destaca-se o consentimento hipotético. Na Alemanha, a posição processual do paciente está mais onerada: no caso de o paciente alegar 
que se tivesse recebido a informação adequada teria recusado a intervenção, é exigido que este demonstre que ficaria numa situação de conflito de decisão, ou seja que mostre ser plausível a sua recusa. Sobre o médico, por seu turno, impende o ônus da prova de que o paciente teria realizado a operação mesmo que tivesse recebido toda a informação. ${ }^{10}$ Esta inversão do ônus da prova justifica-se, uma vez que para o doente esta seria uma prova de facto negativo e indefinido. Estamos perante uma situação de causalidade psíquica, pelo que o tribunal deve decidir com base em "balanços de verosimilhança". O comportamento hipotético do paciente deve ser analisado não de acordo com o paciente razoável ("vernünftigen Patienten"), mas sim tendo em conta a situação de decisão pessoal, ou seja, prevalece o critério do paciente concreto. ${ }^{11} \mathrm{~A}$ essência e a finalidade do esclarecimento é assegurar um espaço de decisão individual, e este deve ser garantido, e o médico deve suportar o ônus da prova do consentimento hipotético. ${ }^{12}$

A responsabilidade, pois, é excluída se o médico convincentemente indica que, se tivesse dado a informação necessária, o paciente teria consentido no procedimento médico e o paciente não consegue tornar plausível que ele teria ficado em dúvida (em situação de conflito de decisão), ou seja, aplica-se o consentimento hipotético.

Seguindo esta doutrina, a Lei alemã de 2013 - "Lei para a Melhoria dos Direitos das Doentes e dos Doentes, de 20 de Fevereiro de 2013" - prevê, no $\S 630 \mathrm{~h}$ referente ao Ônus da prova na responsabilidade por erro de tratamento ou erro de esclarecimento:

(2) O prestador de cuidados de saúde tem de provar que obteve o consentimento, de acordo com o $\S$ 630d, e prestou os esclarecimentos, em conformidade com os requisitos do $\S 630 \mathrm{e}$.

No caso de a prestação de esclarecimentos não estar em conformidade com os requisitos do $\S 630 \mathrm{e}$, o prestador de cuidados de saúde pode alegar que o

${ }^{10}$ DEUTSCH, Erwin / SPICKHOFF, Andreas, Medizinrecht, Arzneimittelrecht, Medizinprodukterecht und Transfusionsrecht, 6. Auflage, Springer, 2008, p. 207. 11 Cf. ENGLJÄHRIGER, Daniela, Ärztliche Aufklärungspflicht vor medizinischen Eingriffen, Verlag Orac, Wien, 1996., p. 118.

${ }^{12}$ KATZENMEIER, Christian, Arzthaftung, Tübingen, Mohr Siebeck, 2002, p. 348-349. 
doente teria consentido no tratamento, caso houvesse sido adequadamente esclarecido.

Também na Inglaterra, a House of Lords com a decisão Chester $v$ Afshar [2004] UKHL 41 consagrou a jurisprudência segundo a qual, se a paciente não foi informada dos riscos de uma cirurgia (neste caso risco de paralisia na sequência de uma cirurgia à coluna) que se vieram a verificar na sequência da mesma, provando-se que a paciente "at that time" não teria aceitado submeter-se à operação, tanto basta para condenar o médico pelos danos causados. Não é necessário que a paciente prove que nunca teria aceitado aquela intervenção. Apenas que não a aceitaria naquele momento e que a operação (que conduziu aos danos) não se teria realizado se ela tivesse sido devidamente informada. No caso tratava-se de uma intervenção de neurocirurgia à coluna com o risco de 1 a $2 \%$ de paralisia, o que se veio a verificar. Tendo-se provado que o médico não informou desse risco, mas que a paciente teria aceitado a intervenção, mas mais tarde, foi o primeiro condenado.

defendida, ${ }^{13}$ explica que:

O Acórdão português de 2/6/2015, seguindo a doutrina por nós

O ônus da prova do consentimento hipotético (...) pertence ao médico e obedece aos seguintes requisitos:

1) que tenha sido fornecida ao paciente um mínimo de informação;

2) que haja a fundada presunção de que o paciente não teria recusado a intervenção se tivesse sido devidamente informado;

3) que a intervenção fosse: i) medicamente indicada;

ii) conduzisse a uma melhoria da saúde do paciente;

iii) visasse afastar um perigo grave;

4) a recusa do paciente não fosse objetivamente irrazoável, de acordo com o critério do paciente concreto.

${ }^{13}$ Sobre a matéria, vide PEREIRA, André Gonçalo Dias, Direitos dos Pacientes e Responsabilidade Médica, Coimbra, 2015, p. 485 ss. 
Por isso, também no caso decidido, que consistia numa intervenção cirúrgica suscetível de causar riscos graves, como dores intensas e incapacidade para manter relações sexuais, andar e trabalhar, concluiu-se que a autora, se soubesse dos riscos da mesma, teria recusado o consentimento, logo não se aplicou o instituto do consentimento hipotético e condenou-se o réu a pagar uma indemnização pelos danos patrimoniais e, sobretudo, não patrimoniais causados, no valor de $€ 26.000$ (dos quais $€ 25.000$ por danos não patrimoniais).

Em suma: saudamos vivamente a decisão do STJ. A clareza da sua exposição, a forma como inteligentemente interpretou a declaração negocial do consentimento escrito, a aplicação cuidada das figuras do consentimento tácito, do consentimento presumido e do consentimento hipotético, conduziu ao resultado justo de condenar o médico por uma intervenção não consentida. Assim, podemos hoje estar seguros de que não há razão para temer que a Convenção sobre os Direitos do Homem e a Biomedicina que estabelece o direito à reparação pelo dano injusto (art 24. ${ }^{\circ}$ ), incluindo pela violação do consentimento informado (art. $5 .^{\circ}$ ) fosse apenas mais um documento de valor decorativo, no ordenamento jurídico português, do que verdadeiramente gozar da força da vigência em condenações judiciais.

O Supremo Tribunal de Justiça português, 101 anos depois acompanha - finalmente - a visão do descendente de portugueses, o Juiz Cardozo, que no caso Schloendorff versus Society of New York Hospital de 2014 (devidamente explicado nesta obra do Professor Dalmir Lopes Jr.), afirmou que a mulher adulta é dona do seu corpo e tem o direito de decidir se quer ou não realizar determinado tratamento ou cirurgia!

\section{REFERÊNCIAS BIBLIOGRÁFICAS}

DEUTSCH, Erwin / SPICKHOFF, Andreas, Medizinrecht, Arzneimittelrecht, Medizinprodukterecht und Transfusionsrecht, 6. Auflage, Springer, 2008.

ENGLJÄHRIGER, Daniela, Ärztliche Aufklärungspflicht vor medizinischen Eingriffen, Verlag Orac, Wien, 1996.

KATZENMEIER, Christian, Arzthaftung, Tübingen, Mohr Siebeck, 2002. 
OLIVEIRA, Guilherme de. O fim da "arte silenciosa. Temas de Direito da Medicina, 2. ed. Coimbra: Coimbra Editora, 2005.

PEREIRA, André Gonçalo Dias, Direitos dos Pacientes e Responsabilidade Médica, Coimbra, 2015. 


\section{A REPERCUSSÃO DA CONSTITUCIONALIZAÇÃO SOBRE OS DIREITOS DA PERSONALIDADE: EM BUSCA DA DIGNIDADE DA PESSOA}

HUMANA

THE REPERCUSSION OF THE CONSTITUTIONALIZATION ON PERSONALITY RIGHTS: IN SEARCH OF THE DIGNITY OF THE HUMAN

PERSON

\section{Danielle Spencer Holanda ${ }^{1}$}

ISSUE DOI: $10.21207 / 1983.4225 .516$

\section{RESUMO}

O presente artigo analisa a influência da constitucionalização sobre os direitos da personalidade. Discorre sobre o processo de constitucionalização do direito. Esclarece sobre sua (a)tipicidade. Ressalta a importância da aplicação dos princípios constitucionais sobre o tema. Demonstra a conexão entre seu conteúdo e os valores da dignidade da pessoa humana.

\footnotetext{
${ }^{1}$ Doutoranda em Direito pela UFPE. Professora das Faculdades Damas da Instrução Cristã, Uninassau e Universo. Coordenadora do Núcleo de Direito do Consumidor da ESA-PE.
} 
Palavras chave: Direitos da personalidade. Constitucionalização. Dignidade da pessoa humana.

\section{ABSTRACT}

The present article analyzes the influence of the constitutionalization on the rights of the personality. Discusses the process of constitutionalisation of law. Clarifies about your typicality. It emphasizes the importance of the application of the constitutional principles on the subject. Demonstrates the connection between its content and the values of the dignity of the human person.

Keywords: Rights of the personality. Constitutionalisation. Dignity of human person.

\section{DA CONSTITUCIONALIZAÇÃO DO DIREITO CIVIL}

O processo de constitucionalização pode ser traduzido, segundo Pietro Perlingieri (2008, p. 177) pela análise da ordem social sob dois enfoques: o "ter" (aspecto patrimonial e mercantil da organização social, pertencente à estrutura econômica e produtiva) e o "ser" (aspecto existencial da pessoa).

O primeiro consagra um Estado, cuja função é manter a ordem, não se interessando em intervir nas situações pré-constituídas, mantémse, portanto, a ordem dos direitos adquiridos. É o chamado Estado liberal, ou de polícia ou guardião noturno, o qual concede uma liberdade ao cidadão em relação ao Estado, cuja preocupação maior é oferecer garantias ao cidadão mediante a estrutura estatal. Já o segundo conduz a um Estado, cujo objetivo é resguardar a pessoa em toda a sua dimensão ontológica e, através dela, seu patrimônio e, para isso, fez-se necessário regular a ordem econômica e social. É o que se denomina de Estado social, o qual impõe limites à liberdade individual, tendo em vista caráter solidário que norteia o sistema. Em outras palavras, a constitucionalização representa, 